\title{
Semi-automated Computed Tomography Volumetry as a Proxy for Intracranial Pressure in Patients with Severe Traumatic Brain Injury
}

Citation for published version (APA):

van de Wijgert, I. H., Jansen, J. F. A., Tas, J., Zeiler, F. A., Voorter, P. H. M., van Hal, V. H. J., \& Aries, M. J. (2021). Semi-automated Computed Tomography Volumetry as a Proxy for Intracranial Pressure in Patients with Severe Traumatic Brain Injury: Clinical Feasibility Study. Acta Neurochirurgica, Supplement, 131, 17-21. https://doi.org/10.1007/978-3-030-59436-7_4

Document status and date:

Published: 01/01/2021

DOI:

10.1007/978-3-030-59436-7 4

Document Version:

Publisher's PDF, also known as Version of record

\section{Document license:}

Taverne

Please check the document version of this publication:

- A submitted manuscript is the version of the article upon submission and before peer-review. There can be important differences between the submitted version and the official published version of record.

People interested in the research are advised to contact the author for the final version of the publication, or visit the DOI to the publisher's website.

- The final author version and the galley proof are versions of the publication after peer review.

- The final published version features the final layout of the paper including the volume, issue and page numbers.

Link to publication

\footnotetext{
General rights rights.

- You may freely distribute the URL identifying the publication in the public portal. please follow below link for the End User Agreement:

www.umlib.nl/taverne-license

Take down policy

If you believe that this document breaches copyright please contact us at:

repository@maastrichtuniversity.nl

providing details and we will investigate your claim.
}

Copyright and moral rights for the publications made accessible in the public portal are retained by the authors and/or other copyright owners and it is a condition of accessing publications that users recognise and abide by the legal requirements associated with these

- Users may download and print one copy of any publication from the public portal for the purpose of private study or research.

- You may not further distribute the material or use it for any profit-making activity or commercial gain

If the publication is distributed under the terms of Article $25 \mathrm{fa}$ of the Dutch Copyright Act, indicated by the "Taverne" license above, 


\title{
Semi-automated Computed Tomography Volumetry as a Proxy for Intracranial Pressure in Patients with Severe Traumatic Brain Injury: Clinical Feasibility Study
}

\author{
Ilse H. van de Wijgert, Jacobus F. A. Jansen, Jeanette Tas, Fred A. Zeiler, Paulien H. M. Voorter, Vera H. J. van Hal,
} and Marcel J. Aries

\section{Introduction}

Severe traumatic brain injury (TBI) is a leading cause of death and disability globally. Severe TBI is defined as a Glasgow Coma Scale (GCS) score $\leq 8$ after resuscitation and abnormalities on computed tomography (CT) scanning of the brain. Admission to an intensive care unit (ICU) is necessary because the patient is in a deep coma and needs ventilation and oxygenation support. During the admission, further swelling can cause secondary damage to recovering or healthy brain tissue because of a low cerebral perfusion state and subsequent ischaemia. To monitor the intracranial volume (ICV), international guidelines recommend continuous invasive monitoring of intracranial pressure (ICP) [1]. Intracranial hypertension indicates that the total ICV is increasing. The skull volume consists of brain tissue, cerebrospinal fluid (CSF), venous blood and arterial blood. In healthy brains, the total volume and flow are kept constant by (limited) compensatory mechanisms such as CSF and venous blood displacements, and by active cerebral autoregulation. This is known as the Monro-Kellie doctrine and is based on the fact that the rigid skull prevents an unlimited rise in the ICV [2]. In severe TBI with brain swelling, compensatory mechanisms are easily exhausted, which leads to a further

I. H. van de Wijgert · J. Tas

Department of Intensive Care, Maastricht University Medical Centre, Maastricht, The Netherlands

\section{J. F. A. Jansen}

Department of Radiology and Nuclear Medicine, Maastricht

University Medical Centre, Maastricht,

The Netherlands

Department of Neurosurgery, Maastricht University Medical Centre, Maastricht, The Netherlands

School for Mental Health and Neuroscience (MHeNs), Maastricht University, Maastricht, The Netherlands

Department of Electrical Engineering, Eindhoven University of Technology, Eindhoven, The Netherlands rise in ICV and a detrimental cascade of a decrease in arterial blood, leading to tissue hypoxia and, finally, neuronal cell death. Clinical protocols are commonly used to control ICP and to guarantee adequate cerebral perfusion pressure (CPP; defined as mean arterial pressure (MAP) minus ICP) [3]. To date, no robust alternatives to reliable and continuous ICV measurements, other than invasive ICP monitoring, are available. Trauma protocols recommend that patients with severe TBI receive CT scanning of the brain at the time of hospital admission. This is a quick and accessible way to provide an impression of the brain condition and the need for neurosurgical intervention. It can show cerebral oedema, a midline shift, haematomas, contusions and skull fractures. Radiologists are often asked whether (indirect) signs of increased brain swelling are present that might warrant intensification of ICP treatment, especially in combination with rising trends in absolute ICP levels. Detailed cerebral CT segmentations could potentially monitor the dynamics of the contused brain more closely. The ratio between the CSF volume and the ICV has previously been introduced to allow inter-individual comparisons [4]. However, manual segmentation is very time consuming. Therefore, we explored calculation of this ratio using automated CT segmentation with very limited manual input.

\section{F. A. Zeiler}

Section of Neurosurgery, Department of Surgery, Rady Faculty of Health Sciences, University of Manitoba, Winnipeg, MB, Canada

Division of Anaesthesia, Department of Medicine, Addenbrooke's Hospital, University of Cambridge, Cambridge, UK

P. H. M. Voorter · V. H. J. van Hal

Department of Radiology and Nuclear Medicine, Maastricht University Medical Centre, Maastricht, The Netherlands

\section{J. Aries ( $\square)$}

Department of Intensive Care, Maastricht University Medical Centre, Maastricht, The Netherlands

School for Mental Health and Neuroscience (MHeNs), Maastricht University, Maastricht, The Netherlands

e-mail: marcel.aries@mumc.nl 
In this pilot study, the clinical feasibility of using a semiautomated CT segmentation algorithm was investigated in patients with severe TBI and related to the current golden standard in skull volume measurements: invasively measured ICP. We hypothesized that volumetric CT measures are associated with ICP.

\section{Materials and Methods}

\section{Patients and Data Acquisition}

This study was conducted in a single academic hospital during the period between April 2017 and May 2019. Brain monitoring metrics and clinical and diagnostic data were collected from adult patients with severe TBI. The study was approved by the local medical ethics committee, and informed consent was obtained by proxy. All patients were sedated, intubated and mechanically ventilated. An intraparenchymal ICP sensor (Codman or Raumedic) was placed, and the patients were connected to a research laptop with Intensive Care Monitoring $\left(\mathrm{ICM}+{ }^{\circledR}\right)$ software, which collected high-frequency $(>100-\mathrm{Hz})$ data (e.g., ICP, blood pres- sure and temperature) from Philips bedside monitors. The moment of ICP sensor placement was not standardized and was thus dependent on clinical or operative indications. All physiological data were extracted from the $\mathrm{ICM}+{ }^{\circledR}$ software, down-sampled to 1-min values and, for the purpose of this study, averaged over $24-\mathrm{h}$ periods from the start of ICM+ ${ }^{\circledR}$ monitoring. The first subsequent $24 \mathrm{~h}$ of monitoring were considered to be day 1 values. These values were compared with the values calculated from the admission CT scan $\left(\mathrm{CT}_{1}\right)$. The average time between $\mathrm{CT}_{1}$ and the start of ICM $+{ }^{\circledR}$ data collection was 16 (range 3-62) h. Values in patients monitored for $<24 \mathrm{~h}$ were averaged over the available hours $(n=3$, minimum time $12 \mathrm{~h}$ ).

\section{CT Volumetry}

$\mathrm{CT}_{1}$ values were used for the analysis. The $\mathrm{CT}$ acquisitions were obtained in DICOM file format. CT acquisitions with a slice thickness of $5 \mathrm{~mm}$ were used for optimal signal-to-noise properties. Brain volumes were segmented using a semi-automated algorithm (Fig. 1), based on the fast marching method of region growing in the Matlab programming language
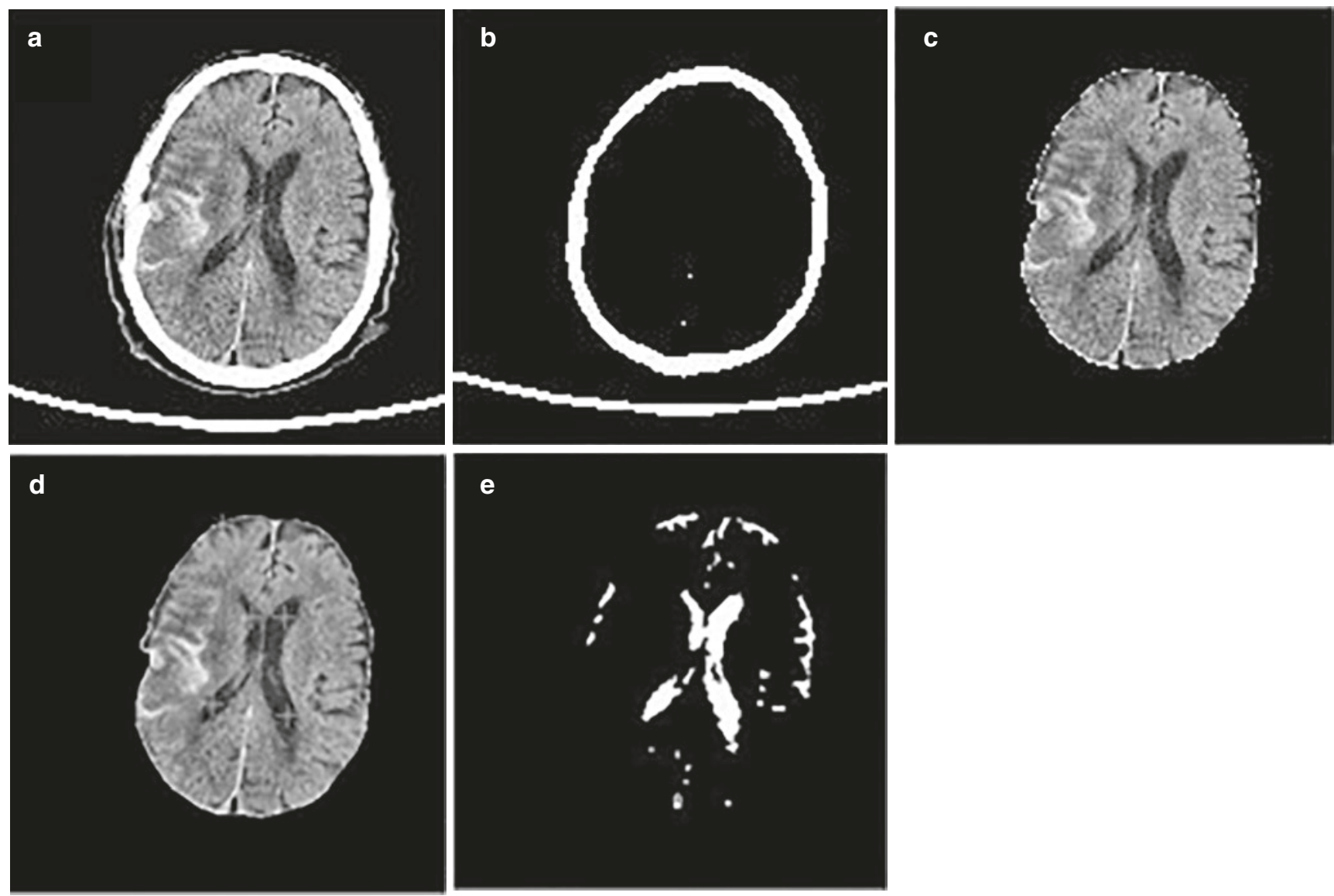

Fig. 1 Semi-automated procedure for tissue segmentation of computed tomography (CT) images. (a) Original transverse CT slice. (b) Identification of the skull on the basis of signal thresholding. (c) The resulting segmentation of intracranial volume after region growing. (d) Manual input (crosshairs) identifying the cerebrospinal fluid (CSF). (e) The resulting segmentation of CSF 
(MathWorks, Natick, MA, USA), through which the volume of the CSF and the ICV are estimated slice by slice [5]. Manual input (by IHvdW) was needed to identify the most caudal and the most rostral slices (to establish the spatial range) and a slice at the lateral ventricle level, in which CSF was identified through selection of 5-50 voxels. Segmentation of the tissue was based on distinct Hounsfield unit values in the parenchyma, CSF and bone. In the case of skull defects (e.g., craniectomy), manual input was required to close the skull. In a final manual quality-control step, slices with artefacts were excluded. The total ICV volume and CSF volume were retrieved using the algorithm through addition of volumes per slice and calculation of the CSF/ICV ratio (expressed as a percentage) by division of the total CSF volume by the total ICV volume $\times 100$ (Fig. 1). To limit intra-observer variability, a single rater (IHvdW) performed the CSF/ICV ratio determination three times per CT scan in all patients. The intraclass correlation coefficient (ICC) was 0.98 (95\% confidence interval 0.97-.99), indicative of excellent intra-rater agreement. The validity of the method has previously been demonstrated by showing that semi-automated segmentation yields CSF/ICV ratios very similar to those obtained through manual segmentation by two independent raters (percentage point difference in $\mathrm{CSF} / \mathrm{ICV}$ calculation $\leq 5 \%$ ) [6].

\section{Data Analysis}

The relationship between the CSF/ICV ratio and ICP was assessed using nonparametric Spearman's correlation. Calculations were performed with independent data, i.e., one data point per patient for $\mathrm{CT}_{1}$ and the mean ICP on day 1 of the data collection. Furthermore, in an explanatory assessment, the relationship between ICP and CSF/ICV was evaluated using a mono-exponential function derived from an animal experimental study in which the intracranial volumepressure relationship was obtained with volume infusions in animals with ICP monitors [7]:

$$
\mathrm{ICP}=\mathrm{ICP}_{\mathrm{cq}} \times \mathrm{e}^{\mathrm{E} 1 \times(1-\mathrm{CSF} / \mathrm{ICV})}+C
$$

where $\mathrm{ICP}_{\mathrm{cq}}$ is a constant equal to the ICP at the equilibrium point (that is, the normal physiological steady state ICP), E1 is the elastance coefficient (a constant defining the slope of the volume-pressure curve) and $\mathrm{C}$ is a constant defining the intercept. In this formula, $\mathrm{CSF} / \mathrm{ICV}$ is the estimate of the intracranial volume and ICP equals the measured invasive ICP. For evaluation of the different models, the squared norm of the residual (resnorm) was compared. No calculation of the required effect size or power analysis was performed in this exploratory study. The data were analysed using IBM SPSS Statistics version 25 and Matlab software.

\section{Results}

Patient characteristics are shown in Table 1. Thirty-three patient data sets were available. The median brain monitoring time per patient was 53 (range 12-293) h. An overview of the population-averaged physiological parameters and $\mathrm{CSF} / \mathrm{ICV}$ ratios is shown in Table 2.

\section{Relationship Between the CSF/ICV Ratio and Invasive ICP on the Admission CT Scan}

A significant correlation between the CSF/ICV ratio and ICP was found $(r=-0.44, p=0.01)$ (Fig. 2). The monoexponential function provided a better fit of the relationship between ICP and the CSF/ICV ratio than the linear model

Table 1 Patient characteristics $(N=33)$

\begin{tabular}{|c|c|}
\hline Variable & Value \\
\hline Female/male ratio $[n / n]$ & $8 / 25$ \\
\hline Median age [years (range)] & $43.4(18-91)$ \\
\hline \multicolumn{2}{|l|}{ Mechanism of injury $[n(\%)]$} \\
\hline Traffic accident & $17(51.5)$ \\
\hline Fall & $15(45.5)$ \\
\hline Other & $1(3.0)$ \\
\hline Median GCS score at admission (range) & $7(3-14)$ \\
\hline Mortality $[n(\%)]$ & $10(30.3)$ \\
\hline \multicolumn{2}{|l|}{ GOS score at 6 months $[n(\%)]^{\mathrm{a}}$} \\
\hline 1 & $10(30.3)$ \\
\hline 2 & $0(0.0)$ \\
\hline 3 & $3(9.1)$ \\
\hline 4 & $4(12.1)$ \\
\hline 5 & $7(21.2)$ \\
\hline \multicolumn{2}{|l|}{ Pupil reactivity $[n(\%)]$} \\
\hline Unreactive & $3(9.1)$ \\
\hline Unilaterally reactive & $3(9.1)$ \\
\hline Bilaterally reactive & $27(81.8)$ \\
\hline \multicolumn{2}{|l|}{ Marshall Classification $[n(\%)]$} \\
\hline I & $2(6.1)$ \\
\hline II & $22(66.7)$ \\
\hline III & $3(9.1)$ \\
\hline IV & $1(3.0)$ \\
\hline V: Evacuated mass lesion & $5(15.2)$ \\
\hline
\end{tabular}

CT computed tomography, GCS Glasgow Coma Scale, GOS Glasgow Outcome Scale

${ }^{\text {a}}$ Values from 9 patients re-admitted to intensive care within the relevant 6-month period are omitted 
Table 2 Mean physiological parameters and the cerebrospinal fluid/ intracranial volume (CSF/ICV) ratio on day 1 of data collection from 33 patients

\begin{tabular}{ll}
\hline Parameter & Mean value (standard deviation) \\
\hline CSF/ICV ratio [\%] & $6.3(4.3)$ \\
Intracranial pressure [mmHg] & $11.0(6.6)$ \\
24-h TIL score & $7.7(2.5)$ \\
Arterial blood pressure [mmHg] & $80.9(8.6)$ \\
Heart rate [beats/min] & $74.0(18.3)$ \\
\hline
\end{tabular}

TIL score Therapy Intensity Level score (see Zuercher et al. [8])

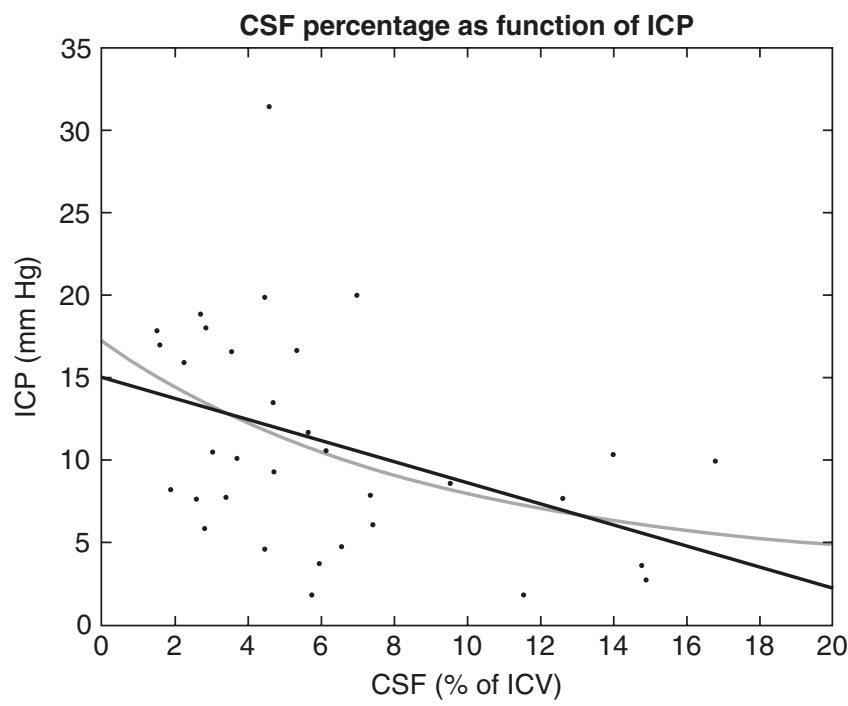

Fig. 2 Scatter plot of the mean intracranial pressure (ICP) (measured in $\mathrm{mmHg}$ ) and the cerebrospinal fluid/intracranial volume (CSF/ICV) ratio (expressed as a percentage) on day 1 . Individual data points indicate individual patients. Least-squares lines for linear regression (black line) and the mono-exponential formula, based on previous work by Avezaat et al. [7] (grey line), have been added for visualization, revealing that ICP increases with a decreasing $\mathrm{CSF} / \mathrm{ICV}$ ratio

(resnorm 1156 vs. 1173), with the following estimates: $\mathrm{ICP}_{\mathrm{cq}}=12.2 \mathrm{mmHg}, \mathrm{E} 1=0.113$ and $C=3.5$.

\section{Discussion}

The aim of this pilot study was to test the feasibility of using a semi-automated CT segmentation algorithm for volume estimation in severe TBI. ICP is significantly associated with the CSF/ICV ratio and best described by a mono-exponential function published previously by Avezaat et al. [7]. In comparison with controlled experimental settings, our patients with TBI were treated in accordance with a protocol recommending that ICP be kept at $<20 \mathrm{mmHg}$, limiting our analysis to a small span of ICP values (Fig. 2). Our method provides a clear advantage over the classical manual segmentation methods and reduces the manual labour from hours to a few minutes per patient.
The literature on brain $\mathrm{CT}$ volumetric segmentation is very limited. In a study by Pappu et al. [4], 45 brain CT scans from 20 patients with severe TBI were selected. A similar negative correlation between the CSF/ICV ratio and ICP was found [4]. However, those values were not obtained independently (more scans per patient were used in the analysis). The authors discussed a cut-off value of 3.5\% for the CSF/ ICV ratio. Ratios higher than this cut-off were considered to have 'normal' ICP values, whereas no definite conclusion regarding ICP could be made with ratios lower than $3.5 \%$. In our study, we were not able to define a cut-off point, probably because we had only a relatively small variety of ICP values available. Jain et al. [9] proposed automated image analysis to quantify the extent of intracranial abnormalities. Their method focused on detecting the volumes of intracranial lesions and the presence of basal cisterns and a midline shift [9], but relationships with ICP measurements and CSF/ ICV ratios were not reported. Prior patient and animal experimental studies have studied the well-cited cerebral volumepressure curve, which is best described by a mono-exponential function $[7,10,11]$. In our study, the mono-exponential function provided a better fit of the relationship between ICP and the CSF/ICV ratio than a linear model.

Our study had the limitations of being a retrospective study in a clinical setting. The variations in the timing between the admission CT scan and the start of the neuromonitoring data collection must have had an effect on the data that were collected. We tried to limit this influence by averaging the ICP values over a longer time period. Furthermore, individual patient variability has not yet been considered, although it is already known that age (i.e., brain atrophy) and clinical outcome influence the CSF/ICV ratio. Despite that, use of the presented algorithm as a clinical tool is feasible. It needs further testing in larger and more diverse patient data sets. Furthermore, segmentation features that include more tissue types (e.g., bleeding or contusions) and a further reduction in the manual input that the algorithm requires could be great improvements. Potentially, machine learning methods could be implemented in the future. Lastly, patients who subsequently develop traumatic hydrocephalus are currently assigned a higher (and more favourable) CSF/ICV ratio but have corresponding intracranial hypertension, manifested by ICP. Although hydrocephalus is found in approximately $20 \%$ of patients with severe TBI [12], only two patients in our population developed hydrocephalus at a later stage of their admission; therefore, those events did not affect the data presented here. In future studies, however, such events could cause a discrepancy in data interpretation; thus, it must be considered in order to exclude patients with different kinds of hydrocephalus from CT volumetry methods.

Semi-automated CT volumetry can be used in future studies to develop more objective criteria to guide indications for continuous invasive ICP monitoring in neuro-intensive care patients, especially when volumetry indexes are tracked over 
time. In addition, it could be an (objective) indicator of brain swelling in situations where contra-indications for placing an ICP monitor exist, such as a high risk of (intracranial) bleeding, hepatic encephalopathy or meningo-encephalitis. It could also be used to objectively quantify the effects of intracranial hypertension therapies.

\section{Conclusion}

Semi-automated CT volumetric measures correlate with ICP in patients with severe TBI. This proof-of-principle study demonstrates the feasibility of this approach in a clinical setting, but validation in larger and different data sets is needed. This non-invasive method could be used in the future to monitor patients who are not candidates for invasive monitoring or to evaluate therapy effects objectively.

\section{Acknowledgments Compliance with Ethical Standards}

Conflict of Interest: The authors declare that they have no conflict of interest

Ethics Approval: All procedures performed in studies involving human participants were in accordance with the ethical standards of the institutional research committee, approval number 16-4-243, Maastricht University Medical Centre, Maastricht, the Netherlands.

\section{References}

1. Carney N, Totten AM, O'Reilly C, Ullman JS, Hawryluk GW, Bell MJ, Bratton SL, Chesnut R, Harris OA, Kissoon N, Rubiano AM, Shutter L, Tasker RC, Vavilala MS, Wilberger J, Wright DW,
Ghajar J (2017) Guidelines for the management of severe traumatic brain injury, fourth edition. Neurosurgery 80:6-15. https:// doi.org/10.1227/NEU.0000000000001432

2. Mokri B (2001) The Monro-Kellie hypothesis: applications in CSF volume depletion. Neurology 56:1746-1748

3. Stocchetti N, Maas AI (2014) Traumatic intracranial hypertension. N Engl J Med 371:972. https://doi.org/10.1056/NEJMc1407775

4. Pappu S, Lerma J, Khraishi T (2016) Brain CT to assess intracranial pressure in patients with traumatic brain injury. J Neuroimaging 26:37-40. https://doi.org/10.1111/jon.12289

5. Voorter PHM (2019) Non-invasive determination of the intracranial pressure using CT images in patients with traumatic brain injury. University of Technology Eindhoven, Eindhoven

6. Berendsen AJ (2017) Volume segmentation of brain CTs for noninvasive ICP monitoring in TBI patients. University of Technology Eindhoven, Eindhoven

7. Avezaat CJ, van Eijndhoven JH, Wyper DJ (1979) Cerebrospinal fluid pulse pressure and intracranial volume-pressure relationships. J Neurol Neurosurg Psychiatry 42:687-700. https://doi. org/10.1136/jnnp.42.8.687

8. Zuercher P, Groen JL, Aries MJ, Steyerberg EW, Maas AI, Ercole A, Menon DK (2016) Reliability and validity of the Therapy Intensity Level Scale: analysis of clinimetric properties of a novel approach to assess management of intracranial pressure in traumatic brain injury. J Neurotrauma 33:1768-1774. https://doi. org/10.1089/neu.2015.4266

9. Jain S, Vyvere TV, Terzopoulos V, Sima DM, Roura E, Maas A, Wilms G, Verheyden J (2019) Automatic quantification of computed tomography features in acute traumatic brain injury. J Neurotrauma 36:1794-1803. https://doi.org/10.1089/ neu.2018.6183

10. Lai HY, Lee CY, Hsu HH, Lee ST (2012) The intracranial volume pressure response in increased intracranial pressure patients: part 1. Calculation of the volume pressure indicator. Acta Neurochir 154:2271-2275. https://doi.org/10.1007/s00701-010-0765-8

11. Miller JD, Leech PJ (1974) Surgical Research Society [proceedings]. The intracranial volume-pressure response during experimental brain compression in primates. Br J Surg 61:318

12. Jiao QF, Liu Z, Li S, Zhou LX, Li SZ, Tian W, You C (2007) Influencing factors for posttraumatic hydrocephalus in patients suffering from severe traumatic brain injuries. Chin J Traumatol 10:159-162 